\title{
Família e trabalho social: intervenções no âmbito do Serviço Social
}

\author{
Dalva Azevedo Gueiros \\ Universidade Cruzeiro do Sul (Unicsul, São Paulo)
}

\section{Família e trabalho social: intervenções no âmbito do Serviço Social}

Resumo: Este artigo apresenta reflexões sobre família e trabalho social, com base em investigações no âmbito do Serviço Social ${ }^{1}$. Para tanto, tece considerações teórico-metodológicas e técnico-operativas sobre esses dois tópicos, demarcando a relação família-Estado, bem como a importância das políticas de proteção social e das redes de relações sociais na organização e no reenraizamento social de famílias dos segmentos populares. Além disso, anuncia algumas premissas dessa prática social, indicando que, se associadas à promoção de acesso a políticas públicas, podem contribuir para a conquista da autonomia e da cidadania de famílias socialmente vulnerabilizadas. Palavras-chave: família, rede social, trabalho social.

\section{Family and Social Work: Interventions in the Realm of Social Work}

Abstract: This article reflects on the family and social work, based on research in the field of social work. It presents theoreticalmethodological and technical-operative considerations about these two topics, recognizing the relationship between family and State, as well as the importance of social protection policies and networks of social relations in the organization and social "re-rooting" of families in popular classes. In addition, it presents some premises of this social practice, indicating that, if associated to the promotion of access to public policies, it can contribute to the conquest of autonomy and citizenship of socially vulnerable families.

Key words: family, social network, social work. 


\section{Introdução}

O início de minha vida profissional se deu na década de 1980, no campo da saúde mental, momento em que se constituía um movimento em prol do retorno de pessoas com transtornos mentais ao convívio da família e da comunidade. Em decorrência disso, os profissionais desse campo, sobretudo os assistentes sociais, viram-se impelidos a trabalhar com as famílias na perspectiva de que elas se preparassem para receber parentes que estiveram hospitalizados por longo período ou que viviam a rotina de breves, porém frequentes, internações. Muitos anos depois, passei a atuar no campo sociojurídico no qual também se impunha a necessidade de se trabalhar na defesa da garantia do direito à convivência familiar e comunitária, com o objetivo de evitar o abrigamento de crianças e adolescentes ou de favorecer sua reinserção familiar e comunitária.

Essas experiências propiciaram sistematizar a investigação sobre família e a compreender que tal temática é complexa, quer do ponto de vista teóricometodológico e ético quer em sua dimensão técnicooperativa, inclusive porque pensar em família implica transcender a noção do que é individual e assumir uma concepção relacional, pois se trata da interação entre um conjunto de indivíduos. Nesse sentido, também foi e continua sendo desafiante transpor para o cotidiano profissional um entendimento que abarque as transformações vividas pela família desde o século 19, as quais resultaram na multiplicidade de suas configurações, na diversidade de modos de interação entre as gerações e na redefinição das relações de gênero e da articulação entre os espaços privado e público. Outra tarefa que entendemos merecer atenção especial por parte dos assistentes sociais é trabalhar nesse campo, sobretudo nos projetos sociais direcionados aos segmentos mais pauperizados, na perspectiva de promover o acesso a políticas de proteção social e, ao mesmo tempo, evitar a tutela do Estado em relação a essas famílias.

Em relação a esse aspecto - Estado e família -, há de se considerar as implicações presentes, uma vez que existe uma efetiva intervenção do Estado na família, por meio de medidas jurídicas (legislações relativas ao casamento e à sua dissolução, à proteção da criança, do adolescente e do idoso, entre outras), econômicas (normatizações relativas ao trabalho e à previdência social, por exemplo) e institucionais (referentes à saúde e à escolarização etc.). Nessa direção, Singly (2007, p. 64) entende que

O Estado ajudou e ajuda a diminuir os laços de dependência: da família em relação à solidariedade da parentela e da vizinhança; da mulher em relação ao homem; da criança em relação a seus pais. As transformações desses antigos laços de dependên- cia têm um reverso: uma menor autonomia da família e de seus membros vis-à-vis os representantes do Estado, juízes, psicólogos, professores, sociólogos etc.

Vale salientar que, a partir da Constituição Brasileira de 1988, a legislação regulamentou ou imprimiu aspectos que mostram estas duas faces: uma protetiva e outra que denota ingerência na vida dos indivíduos. O Estatuto da Criança e do Adolescente (ECA - Lei n. 8.069, de 13 de julho de 1990), por exemplo, de um lado reforça a importância da convivência familiar (artigo $4^{\circ}$ ), iguala os direitos dos filhos nascidos fora da sociedade conjugal ou dos adotivos aos dos filhos nascidos dessa sociedade conjugal (artigo 20) e equipara o poder familiar do pai e da mãe (artigo 21); de outro, introduz a noção de proteção legal da criança em relação a seus familiares e evidencia a possibilidade de suspensão e perda do poder familiar (artigo 22) nos casos previstos na legislação civil.

O novo Código Civil (Lei n. 10.406, de 10 de janeiro de 2002), por sua vez, entre os tantos aspectos relativos à família, expressa também nos artigos 1.583 e 1.584, a igualdade de direitos do pai e da mãe no que se refere à guarda dos filhos.

Outras legislações, como a Lei Orgânica da Assistência Social (LOAS - Lei n. 8.742, de 7 de dezembro de 1993) e o Estatuto do Idoso (Lei n. 10.741, de 1. de outubro de 2003) apresentam igualmente aspectos que interferem diretamente no cotidiano da família.

Considerando que a relação entre o Estado e a família ${ }^{2}$ é mediada por profissionais representantes das instituições e executores das políticas sociais, fica, assim, evidente sua responsabilidade na condução dessa mediação e a necessidade de realizá-la com competência. Com efeito, a promoção, a proteção e a defesa de direitos da população, sobretudo daquela que vive em condições de média e alta vulnerabilidade social, são responsabilidades do Estado. Logo, um dos desafios presentes é o de encontrar meios para a utilização de recursos e a implementação de programas previstos pela Política Nacional de Assistência Social (PNAS) e o Sistema Único de Assistência Social (SUAS) ${ }^{3}$ de forma efetiva e eficaz para a proteção social desse segmento populacional, com vistas à difícil tarefa de fazer frente às complexas e graves expressões da questão social.

Aos profissionais, especialmente aos assistentes sociais, cabe identificar essas expressões que, revestidas de múltiplas formas, configuram-se em processos que levam à exclusão de direitos pessoais e sociais e, consequentemente, à violência em seu sentido mais amplo. Compreender esse panorama, inclusive com a perspectiva de iluminar leituras e intervenções que possam contemplar a complexidade e prevenir a gravidade de situações vividas no âmbito familiar, é outro desafio que se colo- 
ca para aqueles que, conscientes do projeto éticopolítico da profissão, buscam viabilizar ações compatíveis com a conquista de autonomia e de cidadania de indivíduos e famílias.

Neste artigo, buscamos levantar algumas considerações sobre família e trabalho social, evidenciando aspectos predominantes do ponto de vista social. Para melhor compreensão, essas questões serão tratadas em tópicos específicos, não obstante a articulação entre ambas no texto.

\section{Família e rede de relações sociais}

A noção de família remete a relacionamento entre pessoas, que não necessariamente compartilham o mesmo domicílio e os mesmos laços sanguíneos ou de parentesco. Essa ampliação da ideia clássica desse agrupamento humano ${ }^{4}$ parece claramente assumida na literatura, nos marcos legais e no discurso cotidiano das pessoas. Contudo, talvez ainda não esteja suficientemente incorporada nas ações institucionais.

Nesse sentido, uma participante de recente pesquisa sobre famílias de crianças abrigadas ${ }^{5}$, ao explicitar os motivos do acolhimento institucional de seus filhos, indicou como uma das causas a instabilidade de trabalho e de domicílio por ela vivida e as rupturas daí decorrentes. Esclareceu que, num dado momento, com o intuito de manter os filhos consigo, retornou à casa dos pais, em outro estado, porque estava separada do companheiro e, para continuar a trabalhar em São Paulo, precisava deixar suas crianças, durante o dia, com uma vizinha. Porém, foi alertada por outras mulheres que esse arranjo poderia resultar na perda de seus filhos. A fala dessa mãe parece ilustrativa de como a população não se sente segura quanto ao respeito, por parte dos "agentes" de um sistema cujo objetivo é ser protetivo, a suas estratégias de sobrevivência, que incluem, por exemplo, relações de obrigações mútuas com a vizinhança.

Considerando esse exemplo é de se perguntar como é que os profissionais do sistema sociojurídico, da educação e da saúde, entre outros, traduzem no cotidiano de sua prática profissional a concepção proposta no Plano Nacional de Promoção, Proteção e Defesa do Direito de Crianças e Ádolescentes à Convivência Familiar e Comunitária (PNCFC) (BRASIL, 2006, p. 130), a partir da qual a família pode ser pensada como:

Um grupo de pessoas que são unidas por laços de consanguinidade, de aliança e de afinidade. Esses laços são constituídos de representações, práticas e relações de obrigaçõos mútuas. Por sua vez, estas obrigações são organizadas de acordo com a faixa etária, as relações de geração e de gênero, que definem o 'status' da pessoa dentro do sistema de relações familiares.

As famílias de camadas populares, que são organizadas em rede (participação de outros parentes e de pessoas da comunidade no convívio e em prol da sobrevivência) e que têm como foco o sistema de obrigações, diferenciam-se das de camadas médias, que se organizam em núcleos centrados no parentesco. Esse conhecimento é relativamente difundido. Além de constar em marcos legais, como no PNCFC, Sarti (1996) e Fonseca (2002) enfatizam essa perspectiva de análise e, de modo geral, pesquisadores que trabalham com famílias pobres ou abaixo da linha de pobreza assumem essa concepção.

Diante disso, uma das questões que se impõe é a de compreender como essa organização da família em rede poderia ser oficialmente assumida pelas instituições - sem necessariamente passar pela legalização do vínculo ou da responsabilidade, como é geralmente exigido pelo sistema judiciário - com vistas a contribuir para o fortalecimento de certas estratégias de sobrevivência dessa população e da própria prevalência da convivência familiar e comunitária.

Nessa perspectiva, podemos entender que pais, sobretudo mães, criam vínculos mais estáveis com algumas pessoas de sua rede de relações primárias, com as quais estabelecem trocas recíprocas, para favorecer tanto o cuidado e a proteção de seus filhos quanto a possibilidade de inserção social, aspectos classicamente assumidos como funções básicas da família. Contudo, para se pensar a influência das redes de relações primárias no processo de inclusão social ou de reenraizamento social (GUEIROS, 2007), necessário se faz examinar as particularidades de cada família em termos de tempo e espaço sociais, principalmente no que se refere à sua configuração e organização, ao seu percurso transgeracional ${ }^{6} \mathrm{e} a ̀$ sua localização territorial.

A experiência tem mostrado que o grau de conexão, as direções, a quantidade e a qualidade das trocas presentes em uma rede social estão associados ao percurso da família e repercutem em suas relações internas e na interação com o meio social. De modo geral, entende-se que as redes sociais exercem um papel de suporte, e também de controle, ao indivíduo e ao seu núcleo social imediato.

Todavia, podemos supor que nos segmentos populares o desemprego e a precarização dos vínculos de trabalho - que se configuram como expressões poderosas das transformações societais e têm sido apontados como fatores preponderantes na esgarçadura dos vínculos familiares e sociais - afetam o conjunto de indivíduos que compõe essa rede social $^{7}$. Portanto, em que pese a solidariedade presente entre esses segmentos, a entreajuda é insuficiente para fazer frente a momentos de crise ou de 
acentuação da vulnerabilidade social em que vivem, em decorrência dos efeitos da colossal desigualdade social brasileira.

Especialmente nessas circunstâncias, cabe ao profissional de Serviço Social direcionar sua ação para inserir as famílias nas redes sociais secundárias (organizações do poder público e da sociedade civil). Por meio da oferta de serviços de qualidade e de suficientes recursos sociais, que devem ter como princípios a universalidade e a integralidade, essa rede de serviços tem a responsabilidade de assegurar condições protetivas às famílias, na perspectiva da efetivação de direitos e de fomentação de processos emancipatórios, com vistas a promover a justiça social.

A experiência obtida nos campos da saúde mental e do sistema sociojurídico indicou a importância de o profissional reconhecer a família como sujeito de direitos e trabalhar na defesa da garantia de seus direitos sociais, inclusive por meio da promoção do acesso a políticas públicas - que tenham como objetivo final a inclusão produtiva. Isso implica assumir a família como uma referência social, concebendo-a em sua historicidade, em sua localização territorial e como mediadora entre seus membros e a coletividade. Compreender a pluralidade em suas formas de organização e as particularidades que emergem da condição de classe social e das relações de gênero e de geração, bem como da singularidade relativa a questões étnicas e culturais, são aspectos também preponderantes para o assistente social lidar com o trabalho social direcionado às famílias.

\section{Trabalho social com famílias socialmente vulnerabilizadas}

A Política Nacional de Assistência Social apresenta a matricialidade sociofamiliar como um dos tópicos relativos ao "Conceito e a Base de Organização do Sistema Único de Assistência Social”. A implicação disso é a necessidade de se conhecer, em profundidade, as famílias às quais estão direcionadas as ações, pois pela própria multiplicidade de configurações, formas de convivência - diretamente relacionadas a suas condições sociais, crenças e hábitos culturais - e por constituírem espaço de contradições e conflitos, tais famílias apresentam significativas diferenças entre si, mesmo fazendo parte de um mesmo segmento social. Identificar no que as famílias se igualam e no que elas se diferenciam parece ser um dos primeiros desafios que se apresenta para os serviços cuja responsabilidade é a de implementação de políticas sociais, por meio da estruturação de ações que possam ser efetivas e eficazes para a população alvo.

Tendo sempre presente a importância de coletivamente mobilizarem-se forças em prol do enfrentamento das causas estruturais da pauperização, no planejamento e na execução de um trabalho social, há de se direcionarem esforços para a articulação entre bens e serviços públicos como forma de assegurar os direitos individuais e sociais à família. Desse modo, torna-se imprescindível a organização da rede de serviços do território, que inclui o constante diálogo entre as diferentes organizações, na perspectiva de evitar descontinuidades, lacunas ou sobreposições de ações.

Uma eficiente organização da rede de serviços pode proporcionar o atendimento em tempo hábil às necessidades apresentadas pela família. A prática tem mostrado que, em prol da efetividade e eficácia do trabalho social, certas demandas precisam ser respondidas com a maior brevidade possível, inclusive porque disso depende o não agravamento da questão em foco. Se esse aspecto não for considerado, o que emergiu como sendo de média complexidade pode se transformar em situação de alta complexidade e, por conseguinte, exigir mais tempo e recursos para seu equacionamento, além de ocasionar maior sofrimento e até danos à pessoa ou à família.

Na prática com a população de segmentos populares, foi possível constatar que um outro desdobramento da não efetividade das ações é a descrença nos serviços oferecidos, o que pode repercutir negativamente na forma como a família participa da proposta do trabalho e no próprio sentimento de "ter direito a direitos". Nesse sentido, cabe indagar se houve o necessário exame e a devida contextualização da(s) questão(ões) apresentada(s) pela família, bem como do caminho que ela já percorreu na tentativa de ver suas demandas atendidas, de modo a evitar sua culpabilização ou responsabilização, sobretudo nos casos em que o envolvimento do usuário naquele dado projeto não esteja atendendo ao inicialmente planejado.

O rigor na análise da situação apresentada pela família e de seu percurso de vida permite a compreensão desse núcleo para além do tempo presente e das demandas emergenciais e pode favorecer a formulação de programas eficazes. Assim sendo, a identificação, a valorização e a potencialização das capacidades ou competências ${ }^{8}$ dos sujeitos, se realizada de forma que eles se sintam partícipes desse processo, podem, com o devido apoio técnico e acesso às políticas públicas de proteção social, contribuir para a emancipação da família e, consequentemente, para o equacionamento de suas adversidades cotidianas.

Uma análise cuidadosa das questões apresentadas por indivíduos e famílias pode evitar também julgamentos precipitados sobre seus modos de vida. É interessante que se indague, por exemplo, quais são os motivos que levam uma mulher-mãe a buscar, de forma repetitiva, novos parceiros. Seria essa uma tentativa de obter proteção em territórios cuja violência é muito grande? Ou seria também uma forma 
de conquistar, por meio da troca afetiva, algum fortalecimento para enfrentar as agruras de seu dia a dia? Será que o homem continua ocupando, nesse segmento social, o papel de principal mediador entre a família e o meio social imediato? Presumimos que o exame dessa e de outras questões pode contribuir para que o profissional efetive ações concernentes às demandas da população usuária daquele dado programa ou serviço.

Um trabalho que abarque esse processo conjunto com a família deve estar diretamente associado às necessidades apresentadas por ela, mas, via de regra, é importante que se realizem, além de sua inclusão em políticas de proteção social, diferentes modalidades de atendimento, algumas de caráter individualizado e outras de caráter coletivo. Esse cuidado é necessário porque um indivíduo, ou uma família, pode melhor se expressar em uma determinada modalidade do que em outra e, assim, ampliam-se as possibilidades de identificação de suas questões e de suas potencialidades.

A atenção individualizada visa abordar as questões que são singulares àquela família, sobretudo as relativas às vicissitudes de seu percurso de vida, ao convívio de seus vários membros e ao processo socioeducacional de crianças e adolescentes. Os procedimentos de caráter coletivo envolvem diversas famílias e têm o objetivo de trabalhar as particularidades daquele conjunto de sujeitos e de estimular a articulação entre eles, inclusive em prol da reivindicação de seus direitos sociais.

Entre as atividades coletivas, observamos que as de cunho sociorrecreativas (programações realizadas em parques e espaços culturais, por exemplo, definidas a partir das aspirações dos participantes) eram muito bem aceitas e favoreciam um efetivo entrosamento intra e inter familiar. Tinham também o objetivo de ampliar o conhecimento e acesso das famílias a bens e serviços de seu território e da cidade onde residem e de possibilitar a qualificação da vinculação entre os participantes e desses com o programa social, além de possibilitar melhores condições para a reflexão sobre sua problemática, inclusive porque o lazer concorre para o exercício intelectual (WEIL, [1949] 1996).

Desse modo, o trabalho social com famílias ${ }^{9}$, abarca procedimentos relativos à rede de bens e serviços do território e atenção individualizada e coletiva à população usuária, realizados de forma regular e frequente. Deve contemplar igualmente a interdisciplinaridade e intersetorialidade (articulação das políticas de saúde, educação, assistência e habitação, entre outras) e zelar pela permanência a médio e longo prazo dos programas e serviços oferecidos, posto que as famílias já vivem múltiplas instabilidades (de trabalho, de domicílio, da rede de suas relações sociais primárias, por exemplo) e não podem ser submetidas também a projetos que não se constituam em políticas de longo alcance, em termos dos recursos necessários e de um tempo viável ao processo de autonomia e de emancipação da família.

Com a clareza de que as considerações feitas neste artigo não contemplam a complexidade inerente a uma prática social com famílias, salientamos, por último, a necessidade de permanente avaliação e monitoramento ${ }^{10}$ do trabalho social como forma de torná-lo condizente com as demandas da população em foco, eficaz em suas ações e efetivo em seus objetivos. Nessa perspectiva, um aspecto que pode e deve ser contemplado é a reflexão, e redefinição se for o caso, de conceitos que orientem os gestores e profissionais no planejamento e execução do trabalho, com vistas a implementar as premissas conceituais e legais das questões em foco, fazer a devida articulação das condições vividas pela população com as relações sociais mais amplas e a defesa intransigente da garantia dos direitos fundamentais dos sujeitos em prol de sua autonomia e cidadania.

\section{Considerações finais}

Nos diversos campos de atuação do assistente social, é notória a complexidade das questões que se apresentam cotidianamente. As demandas advindas de um processo de exclusão social cada vez mais agudizado, decorrente sobretudo do desemprego e da precarização do trabalho - exigem respostas que estejam embasadas na análise da articulação entre os processos econômicos, políticos e culturais preponderantes na sociedade naquele dado momento, aos quais a população está submetida e, portanto, vivendo seus reflexos. 
Nesse sentido, as intervenções no âmbito do Serviço Social devem resultar de uma análise criteriosa das demandas e do percurso de vida dos sujeitos ou das famílias a quem está direcionada a ação profissional, inclusive para obter uma compreensão mais apurada das estratégias de enfrentamento das vulnerabilidades sociais da população alvo, tendo sempre em vista as causas estruturais de sua pauperização e de seu desenraizamento social.

Entendemos também como peculiar a um trabalho social com famílias, além da consideração às condicionalidades já referidas, um entendimento da política assistencial como política de seguridade social e uma direcionalidade para a efetivação de direitos sociais.

Desse modo, consideramos imprescindível que os assistentes sociais gestores ou executores de projetos sociais avaliem constantemente se as ações em curso estão trazendo algum impacto para a superação das vulnerabilidades sociais e em prol do processo de emancipação e de cidadania daqueles indivíduos e famílias.

\section{Referências}

BATTINI, O. SUAS: conquistas sociais e desafios. In: . (Org.). SUAS: Sistema Único de Assistência Social em debate. São Paulo: Veras Editora, 2007. p. 09-18. (v.1)

BRASIL. Plano Nacional de Promoção, Proteção e Defesa do Direito de Crianças e Adolescentes à Convivência Familiar e Comunitária: Ministério do Desenvolvimento Social e Combate à Fome - Secretaria Especial dos Direitos Humanos. Brasília, dez. 2006.

CAVICHIOLLI, A. T. et al. Projeto de apoio e inclusão social - PAIS. In: CONFERENNCIA INTERNACIONAL DE SERVIÇO SOCIAL, 19., 2008, Salvador. Anais: O desafio de concretizar direitos numa sociedade globalizada e desigual. Salvador: CFESS, CRESS 5 5a Região e IFSW, 2008.

FONSECA, C. Caminhos da adoção. São Paulo: Cortez, 2002.

GUEIROS, D. Adoção consentida: do desenraizamento social da família à prática de adoção aberta. São Paulo: Cortez, 2007.

Trabalho social com famílias socialmente desen-

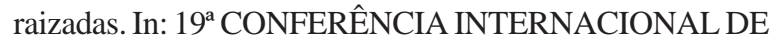
SERVIÇO SOCIAL, 2008. Salvador. Anais: O desafio de concretizar direitos numa sociedade globalizada e desigual. Salvador: CFESS, CRESS 5. Região e IFSW, 2008.

; VITALE, M. A. F.; SETTE, M. B. A. Histórias de famílias por intermédio do genograma. In: FÁVERO, E. T.;
VITALE, M. A. F.; BAPTISTA, M. V. Famílias de crianças $e$ adolescentes abrigados: quem são, como vivem, o que sentem, o que desejam. São Paulo: Paulus, 2008. p. 143174.

MIOTO, R. C. T. Novas propostas e velhos princípios: a assistência às famílias no contexto de programas de orientação e apoio sociofamiliar. In: SALES, M.A.; MATOS, M. C.; LEAL, M. C. (Org.). Política social, família e juventude: uma questão de direitos. São Paulo: Cortez, 2004. p. 43-60. (v. 1).

SANICOLA, L. As dinâmicas da rede e o trabalho social. São Paulo: Veras, 2008.

SARTI, C. A. A família como espelho: um estudo sobre a moral dos pobres. Campinas: Autores Associados, 1996.

SINGLY, F. Sociologia da família contemporânea. Tradução de Clarice Ehlers Peixoto. Rio de Janeiro: FGV, 2007.

WANDERLEY, M. B.;PAZ, R. D. O.;ARREGUI, C. C. Gestão de programas sociais: referenciais teóricos para monitoramento e avaliação. In: CASTANHO e OLIVEIRA, I. I. M.; WANDERLEY, M. B. (Org.). Trabalho com famílias: textos de apoio. São Paulo: IEE/PUCSP, 2004. p. 169-188.

WEIL, S. [1949] L'Enracinement. A condição operária e outros estudos sobre a opressão. Organização de Ecléa Bosi. Tradução de Therezinha G. G. Langlada. Rio de Janeiro: Paz e Terra, 1996.

\section{Notas}

1 Opresente artigo apresenta reflexões sobre família e trabalho social apoiadas principalmente em minha experiência como assistente social em saúde mental e no sistema sociojurídico. As indagações e os conhecimentos advindos da prática cotidiana foram aprofundados e sistematizados em estudos acadêmicos, realizados individualmente ou em conjunto com outros pesquisadores, que tinham o objetivo de compreender as famílias a partir de seus próprios relatos e do entendimento que elas tinham sobre si e sobre seus percursos de vida.

2 No que se refere às interpretações da relação família-Estado, à organização dos serviços e à ação dos técnicos direcionada à família, ver também Mioto(2004).

3 Como o intuito deste artigo não é discutir propriamente a Política Nacional de Assistência Social e o Sistema Único de Assistência Social sugerimos, para uma reflexão mais aprofundada desses marcos legais, sobretudo do segundo, a leitura de Battini (2007). 
4 A ideia clássica de família é a de que os pais vivem juntos e no mesmo domicílio com os filhos, havendo clara distinção entre os papéis atribuídos ao homeme à mulher e uma relação hierárquica e pouco democrática entre as gerações (família nuclear patriarcal). Essa noção foi-se modificando principalmente a partir da segunda metade do século 20 .

5 O conjunto das questões apresentadas por essa participante pode ser visto em Gueiros, Vitale e Sette (2008, p. 153-160).

6 Gueiros, Vitale e Sette (2008) discutem percursos de famílias que tiveram filhos abrigados e um instrumento de pesquisa, o genograma, para captar e compreender tais percursos.

7 As redes sociais, sobretudo as de relações primárias (formadas por parentes, amigos e vizinhos), constituem-se a partir da convivência, com ou sem o estabelecimento prévio de objetivos, e não têm fronteiras bem definidas, o que as diferenciam dos grupos sociais. Representam um tecido social cujo entrelaçamento tem diferentes conexões e direções e cujas trocas não são diretas nem lineares. Existem nas diferentes camadas sociais e podem ter um papel importante na construção da identidade e do bem-estar do indivíduo ou da família. Nas camadas populares, a solidariedade advinda dessas redes de relações sociais primárias está geralmente associada à subsistência individual ou grupal; nas camadas médias, estaria mais voltada para a promoção social.

8 A referência às competências da família diz respeito ao conhecimento que ela (enquanto grupo ou seus membros individualmente) tem de sua problemática e de possíveis caminhos para redefinição da situação, além de habilidades e atitudes das quais pode se utilizar para o desenvolvimento de seus membros e das relações intra e extrafamiliares.

9 Em Gueiros (2008) e Cavichiolli et al. (2008), constam apresentações e discussões de metodologia de trabalho social com família, embasadas especialmente em projeto realizado na região sul da cidade de São Paulo com população em situação de alta vulnerabilidade social. Sanicola (2008) apresenta uma metodologia de trabalho por ela denominada "Intervenção de Rede", aplicada principalmente na Itália, que pode contribuir para se pensar o trabalho social com as famílias brasileiras.

10 De acordo com Wanderley, Paze Arregui (2004,p. 170, 172), avaliação é o "[...] exame sistemático e crítico dos objetivos de uma política ou de um programa, de sua implementação, de seus resultados e de seu impacto social. Deve ser entendida como um instrumento para a tomada de decisões e para o controle social das políticas públicas, aquelas que se desenvolvem em esferas públicas da sociedade.” O monitoramentoé entendido por essas autoras como um “[...] processo de avaliação permanente que permite coletar, armazenar, analisar e utilizar informações do projeto, retroalimentando o próprio projeto desenvolvido. Como parte integral do projeto, subsidia a tomada de decisão política quanto a propósitos, processos de ação e alocação de recursos [...]".

\section{Dalva Azevedo Gueiros}

dalazg@uol.com.br

Doutora em Serviço Social pela Pontifícia Universidade Católica de São Paulo (PUC-SP)

Assistente Social do Tribunal de Justiça do Estado de São Paulo

Professora da Graduação em Serviço Social e do Mestrado em Políticas Sociais da Universidade Cruzeiro do Sul (Unicsul, São Paulo)

\section{Universidade Cruzeiro do Sul}

Rua Galvão Bueno n. 868, 9. Andar

Liberdade

São Paulo - São Paulo

CEP: 01506-000 